OPEN ACCESS

Edited by:

Ilija Djekic,

University of Belgrade, Serbia

Reviewed by:

Minelle E. Silva,

Excelia Business School, France Federica Murmura,

University of Urbino Carlo Bo, Italy

${ }^{*}$ Correspondence:

Maureen Schulze

maureen.schulze@

agr.uni-goettingen.de

tThese authors have contributed equally to this work

Specialty section:

This article was submitted to

Sustainable Organizations,

a section of the journa

Frontiers in Sustainability

Received: 03 March 2021

Accepted: 09 August 2021

Published: 03 September 2021

Citation:

Schulze M, Spiller A and Risius A (2021) Co-ops 2.0: Alternative Retail Strategies to Support a Sustainable

Transition in Food Retailing.

Front. Sustain. 2:675588

doi: 10.3389 /frsus.2021.675588

\section{Co-ops 2.0: Alternative Retail Strategies to Support a Sustainable Transition in Food Retailing}

\author{
Maureen Schulze ${ }^{* \dagger}$, Achim Spiller and Antje Risius ${ }^{\dagger}$ \\ University of Goettingen, Department for Agricultural Economics and Rural Development, Marketing for Food and Agricultural \\ Products, Göttingen, Germany
}

While modern food retailing is characterized by high price pressure and low-quality differentiation resulting in a limited supply of sustainably produced alternative food products, cooperative retailing structures offer additional synergies in terms of logistics and operations that hold great potential to support the expansion of sustainable produce. Many retailers in Germany are organized in cooperatives of sufficient size to generate large-scale effects while still allowing individual retailers to pursue independent business structures. Cooperatives targeted to elaborate on collectivity operate a business. In economic terms this means that scale effects are used to elaborate and help single business. In the food sector cooperative structures in Germany provide a substantial impact in food delivery and provision, especially fresh foods are very sensitive and need fast circulation. Sourcing sustainable, local and regional foods are often produced (or rather crafted) in small scale entities. This paper asks the question of how and whether cooperative marketing structures help to deliver and use scale effects of larger entities, while still collaboratively encouraging food marketing. Accordingly, this paper reports on an investigation of the main challenges faced by members of a large-scale cooperative in retailing sustainably produced products and the motives of these retailers in choosing whether or not to sell such products. Taking the case of grass-fed beef sold by retailers within a large German cooperative, the study reveals that some of the obstacles to selling this sustainable product are comparable to challenges typically encountered in other retailing channels beyond cooperative structures. However, we also find that the flexibility of the cooperative structure enables individual retailers to bring their intrinsic motivation into (sustainable) action in the marketplace while taking advantage of the support offered by the cooperative in terms of marketing and consultation, etc. This analysis confirms that personal motivation within this cooperative structure is a strong determinant for individual retailers to pursue different pathways for the marketing and sale of sustainably produced food.

Keywords: food retailing, sustainability, transition, mixed-method, cooperative structure, retail strategy 


\section{INTRODUCTION}

Food production accounts for some $21-37 \%$ of total greenhouse gas emissions and faces fundamental challenges in terms of sustainability (Godfray and Garnett, 2014). From a sustainable transition perspective, retailers are key actors in facilitating or impeding a sustainability transition (Vadakkepatt et al., 2020).

Globally, the food retail trade is a highly concentrated industry (Sexton and Xia, 2018), and this is especially the case in Germany (Nielsen Trade Dimensions, 2019), meaning that major retailers exercise a strong degree of buyer power over suppliers, since farmers depend on only a limited number of food retailers to sell their products. This dependency enables food retailers to enforce their own standards and subsequently to influence the food market through their own marketing activities (Peattie and Peattie, 2009; Sands et al., 2009).

In this challenging context the organizational structure of cooperatives might increase the capacity of food retailers to overcome long-established structures in the industry and thus enable the emergence of radical improvements in sustainability and may hence be an example for cooperative marketing channels to speed up sustainability transition. (Food) Retail cooperatives differ from conventional food retailers in that they benefit from joint advertising and promotion efforts while affording their members the freedom to make independent decisions regarding their product ranges, thereby enabling individual retailers to initiate radical sustainability innovations. Examples of such cooperatives include the Edeka Group, Germany's largest food retailer, and France's large retailing cooperatives, Système U and E.Leclerc, as well as New Zealand's Foodstuffs. Agricultural cooperatives have a long tradition in handmanship and are essentially targeted to elaborate on collectivity to operate a business.

In economic terms this means that scale effects are used to elaborate and help single business. In humanistic terms, however this means that collaboration and communication is a substantial element in the entities. This, in turn, may have a reciprocal effect and is empowering in light of sustainable transitions using a bottom-up-approach. In the food sector cooperative structures in Germany provide a substantial impact in food delivery and provision, especially fresh foods are very sensitive and need fast circulation. Sustainable food provision is still, despite the gaining societal interest, challenging. Food retail cooperatives in Europe have already undertaken efforts in recent years to facilitate alternatives to the prevailing trend of centralization in the food retail industry. As part of these efforts, cooperatives have launched an increasing number of initiatives to market local food products (Bui et al., 2019) involving intensified collaboration with local farmers. In Germany in particular, several local marketing strategies have been initiated, including by the Edeka Group ("Unsere Region-Gutes von Hier") and the Rewe Group ("Aus deiner Region”). The shorter food supply chains established by such local initiatives are not based on achieving scale effects (quantity) but are aimed instead at more sustainable production (quality) and the environmental, economic, and social benefits of such production (Pearson et al., 2011; Mastronardi et al., 2015). Short food supply chains typically involve a limited number of economic operators with closer than usual geographical proximity between farmers and consumers (Kneafsey et al., 2013). These initiatives thus encourage and foster collaboration with smallscale farmers, who are often otherwise excluded in food retail marketing practices due to their lack of capacity to meet retailers' high demands for large quantities of standardized products (Bui et al., 2019). In this way cooperatives serve to reconnect food producers and consumers, thereby fostering a more transparent mode of food production and consumption (Vittersø et al., 2019). Alternative marketing strategies offer great potential to improve consumer satisfaction and loyalty intentions if they are based on retailers' societyserving motives (Bolton and Mattila, 2015).

To date, however, path dependence and the stability of the existing system have made it difficult for radical sustainability innovations to emerge in the food retail sector (Geels, 2004; Esbjerg et al., 2016).

The German meat market is a special example in this regard as it has so far concentrated primarily on mass production rather than sustainably produced meat, with most meat products advertised on the basis of their low price rather than their quality, highlighting low market differentiation (Eurostat, 2021). The German meat market has thus been characterized more by its adherence to cost leadership strategies than a focus on quality differentiation (Porter, 1980). In this context, promoting local and regional food heritage may be an effective way to foster sustainable product differentiation on the German meat market.

Food retailers organized in cooperatives are and may be key parts in moving toward sustainable patterns of meat production and consumption (Bui et al., 2019). However, the ways in which such cooperatives can steer the transition toward more sustainable modes of meat production and consumption have so far been mostly neglected in recent publications on transition (El Bilali, 2019). A deeper understanding is thus needed of the structural embedment of actors and their cooperative daily chores and reasons why retailers in food cooperatives decide whether to invest in initiatives that promote local and regional heritage food products and foster a transition to a more sustainable food sector.

The aim of this study is to assess the potential of cooperative structures to support effective alternative retail strategies that promote the distribution of sustainable products. Specifically, we identify the special analytical framework of cooperative structures by investigating the key challenges perceived by retailers in selling grass-fed beef and their motives for choosing whether or not to retail it. The analysis of these challenges and motives among retailers organized in a large German cooperative seeks to identify potential drivers and possible routes for alternative distribution channels for sustainable food. The findings of this study thus contribute to a stronger understanding of why some food retailers deviate from the status quo of increasing standardization, centralization, and low-quality differentiation in the food industry, and thus contribute to a better understanding of the development of sustainable supply chains in the retail sector. We further explore how collaborative structures could support a more sustainable alternative, finding 
that the structure of cooperatives may allow a higher level of flexibility for retailers that enables them to overcome the challenges of marketing, distribution, and retailing involved with sustainable produce.

\section{THEORETICAL FRAMEWORK}

The theoretical analysis of the proposed study is settled in a framework established by Geels in 2004 (Geels, 2004). It departs the system of socio-technological change in three basic elements [the production of artifacts (i.e. foods), the distribution, and the use of the artifacts]. The framework is based on institutional economics, but widens to innovation and adaptation by extensions to a dynamic interface as well as societal facets through network analysis. Within, the unit of analysis is expanded from sectoral systems of innovation to "socio-technical systems". Taking this as a really interesting sample for within-analysis the theory, however, expands to the interaction of different systems, hence, from one system to another, which is called the multilevel perspective. Taking the food sector as an example, this framework is particularly useful.

For this study this means, deviating from existing supply chain mechanisms is invariably accompanied by initial hurdles that require additional efforts on the part of retailers. Retailers must invest time and money in developing new marketing and logistical conditions, including price negotiations, as well as incurring costs from supply disruptions, etc. (Bui et al., 2019). Retailers pursuing alternative supply chains may benefit from an enhanced knowledge about how to adapt their existing marketing and communication concepts so as to inform consumers about the benefits of locally produced food and closer proximity to farmers/suppliers. The investment required on the part of retailers thus entails risks and additional organizational and financial efforts, especially since the marketing of niche products is typically accompanied by low initial sales performance (Geels, 2004). Notwithstanding these complexities, some food retailers organized in cooperatives choose to invest in local food while other retailers reject such investment. The adaptation process involved for food retailers opting to invest in more sustainable local produce is currently not well-understood.

The multi-level perspective (MLP) on socio-technical transitions can further suit for describing and analyzing changes toward more sustainable food production and consumption (Lachman, 2013). According to the MLP approach, transitions occur through interactions within and between interactions in several areas; niche regimes and socio-technical landscapes. Within this multi-level perspective, "niches" are considered the locus of innovations, wherein "niche pioneers" find ways of developing alternative approaches (Geels, 2004; El Bilali, 2019), while "regimes" denote incumbent socio-technical systems (Holtz et al., 2008), and "landscapes" refer to exogenous environments such as cultural trends (Geels and Schot, 2007) that exert pressure on regimes and create opportunities for niches (El Bilali, 2019). In accordance with this scheme, a successful transition is defined as a shift from an existing regime to a new regime.

Applying this conceptualization to food retailers, we can describe the initiatives taken by retailers in cooperatives to market local food in opposition to the high levels of centralization and standardization in current conventional food retailing as efforts aimed at changing a regime (El Bilali, 2019). Trends such as the increasing level of public interest in more sustainable meat production can be described as the "landscape" environment (Immink et al., 2013; El Bilali, 2019). Increased pressure from this landscape in turn creates opportunities for retailers to initiate further cooperation with local farmers. In food retail, such alternative marketing approaches have so far remained confined to niches, while the dominant regime in this industry continues to focus primarily on centralization. According to Geels (2004), this makes it possible to compare not only innovations but also the interaction between agents. Hence, Geels and Schot (2007) have distinguished between different transition pathways depending on the timing and nature of multilevel interactions. The "transformation pathway" is of particular interest in regard to the impact of food retailers on the transition toward more sustainable food production and consumption. The transformation pathway describes insufficiently developed niche innovations occurring in parallel with moderate landscape changes that exert pressure on regime actors (i.e., food retailers). Regime actors react in turn by modifying the direction of future developments, while the basic regime architecture remains the same (Geels and Schot, 2007). A well-known example of the transformation pathway is the development of organic food, which was first initiated by green activists in niches and was later picked up by food retailers (i.e., regime actors) (Smith, 2006; Geels and Schot, 2007).

\section{MATERIALS AND METHODS}

Drawing on the theoretical background outlined above, this study adopted an explorative mixed-method approach to investigate the challenges perceived by food retailers in marketing locally produced meat and their motives for undertaking this investment. First, a qualitative explorative pre-study investigated motives and barrier for changing operation pathways. Second, with a quantitative online-study, qualitative results were confirmed and further insights into motives and barriers were gained.

While the findings from the qualitative interviews reported here have already been published in part elsewhere (Schulze and Risius, 2019; Schulze et al., 2019), they were re-analyzed for this study and used as explorative pre-study in order to devise a subsequent quantitative survey. This study opted for a combination of different sampling methods on the basis that a mixed method approach is better suited to address the research question (Palinkas et al., 2011). This study focused on Germany's leading food retail cooperative and its efforts to promote a sustainable transition in food retailing. The cooperative was evaluated as appropriate because of its size and organizational structure. Thereby, this study took the 
example of grass-fed beef as a sustainably produced product. The product can be characterized as a niche product. Until now, the production and marketing of grass-fed beef has been insufficiently developed. Data for the amount of grass-fed beef sold in German supermarkets are not available. However, organic beef production, that allows pasture-access for cows as well, accounts for only $5.5 \%$ of the production of beef in Germany [Agrarmarkt Informations Gesellschaft (AMI), 2021]. Therefore, according to the definition by Geels and Schot (2007) who defined the transformation pathway as insufficiently developed niche innovations occurring in parallel with moderate landscape changes that exert pressure on regime actors, grass-fed beef was used as an appropriate example to investigate niches. As such, food retailers who try to invest in the marketing of grass-fed beef can be characterized as niche-actors.

The cooperative has three management levels and consists of a national head office, seven regional wholesalers, and some 3,700 affiliated retailers. The retailers that participated in this study were from the cooperative's second-largest regional wholesaler which is responsible for marketing food in the south of Germany and has a total of 1,300 grocery stores. In accordance with its cooperative structure, 951 of these retailers are ownermanaged, i.e., owners can make their own decisions regarding the product ranges they stock while benefitting from the cooperative's promotional activities. Consultants employed by the company provide further support for individual retailers with their marketing and communication activities. In addition to the legally independent cooperative members, the remaining retailers in the cooperative are managed by the regional wholesaler, though local shop managers are still able to make some decisions regarding the stocking of the grass-fed beef produce examined in this study. ${ }^{1}$ At the time of data collection, 115 retailers from the retail cooperative had already sold locally produced grass-fed beef, of whom 92 were independent retailers. The retailers could either purchase the beef from the regional wholesaler or make their own contracts with local farmers. ${ }^{2}$

All of the participants in the qualitative interviews and the quantitative survey were members of the regional wholesaler responsible for marketing food in the south of Germany. The study invited participation both from retailers who already sold the product and those who did not. The consultants of the cooperative who participated in the study included those who advised retailers that already stocked grass-fed beef and those that did not. All of the retailers that participated in the study were in a position to make independent decisions about whether or not to add grass-fed beef to their product range. This selection of participants enabled us to obtain a balanced picture of the challenges and motives involved in marketing grass-fed beef. The study was supported by the regional wholesaler in the south of Germany who provided contact details for the participants in the qualitative interviews and shared the link to the online quantitative survey with retailers.

\footnotetext{
${ }^{1}$ Based on an informal dialogue with the cooperative during this investigation. ${ }^{2}$ Based on an informal dialogue with the cooperative and with farmers during this investigation.
}

\section{Study 1}

Twelve qualitative interviews were conducted in June 2018, of which 10 interviews were with retailers and two were with consultants. The interviews with consultants were conducted on the assumption that they possessed a broad understanding of the issues involved in marketing grassfed beef since they were in contact with multiple retailers. The aim of including these consultants in this study was thus to ensure the identification of a wide range of challenges and motives, thereby improving the development of the quantitative survey. The interviews took place over the phone and followed a semi-structured format. The core questions were the following: Why did you decide to market grass fed beef? How do you try to make customers aware of the product? What is the most important issue when marketing grass fed beef?

Each interview lasted $20 \mathrm{~min}$ on average, and all interviews were recorded. Once the data had been gathered, the interviews were transcribed and analyzed through qualitative content analysis in accordance with the methods developed by Mayring (2010) and using the software MAXQDA Plus 2020. The interviews conducted with consultants and food retailers who already stocked grass-fed beef had already been analyzed according to their motives to invest in sustainable marketing initiatives by Schulze et al. (2019). The current study additionally investigated those food retailers who did not stock the product. The following code categories were determined deductively and are presented below in Table 1: "experience in the marketing of grass-fed beef"; "challenges in marketing," including the inductively identified sub-categories of "supply chain related" and "marketing-related" challenges; and "motives in marketing," including the inductively identified sub-categories of "intrinsic motivation (values and attitudes)" and "extrinsic motivation (financial incentives)".

\section{Study 2}

Based on the results of the explorative qualitative pre-study, a standardized questionnaire was developed and operationalized as an online survey in the period from March to June 2019. The development and adaptation of the survey items was based on the results of the qualitative interviews and further considered the perceived challenges related to communication and coordination. The survey was structured in three separate parts. In the first part, retailers were asked about several characteristics of their market (the number of their employees, the size of their sales area, etc.) and their past and future product-range decisions regarding grass-fed beef. The second part asked retailers about the challenges of marketing grassfed beef, while the third part of the survey investigated the retailers' extrinsic and intrinsic motives. Intrinsic motives were investigated by differentiating between values and attitudes, which is a common approach in empirical research (e.g., Papagiannakis and Lioukas, 2012). Values were examined according to the theory of values developed by Schwartz (1992). In accordance with the findings of Papagiannakis and Lioukas (2012), however, only the values of self-transcendence and self-enhancement were considered. At the attitude level, the 
TABLE 1 | Challenges and motives for sustainable marketing structures (code categories).

\begin{tabular}{|c|c|c|c|}
\hline Main category & Sub-category & Approach & Source \\
\hline Experience & - & Deductive & Personal briefing with regional wholesaler \\
\hline \multirow[t]{2}{*}{ Challenges } & Coordination-related & Inductive & \\
\hline & Communication-related & Inductive & \\
\hline \multirow[t]{2}{*}{ Motives } & Extrinsic (financial incentives) & Deductive & Papagiannakis and Lioukas, 2012 \\
\hline & Intrinsic (values and attitudes) & Deductive/inductive & Papagiannakis and Lioukas, 2012 \\
\hline
\end{tabular}

survey assessed retailers' concern for animal welfare on the basis of the animal treatment scale developed by Kendall et al. (2006) and two items developed by Schulze et al. (2019). A detailed overview over the items used can be seen in Table 3. To assess the importance of external financial incentives, we adapted a single item from Papagiannakis and Lioukas (2012): "When selling locally produced grass-fed beef, financial success is most important".

A total of 57 retailers took part in the quantitative survey. Data checks for quality showed good data assurance and no conspicuous response behavior such as inconsistencies or responses given too hastily. However, two of the retailers who had already stocked locally produced grass-fed beef did not plan to stock it again in the future, meaning this group was too small for further statistical analysis, and these two retailers were therefore excluded (see Figure 1), meaning a total of 55 respondents were included in the final data analysis. The quantitative data were analyzed using IBM SPSS Statistics 26 and RStudio 1.2.5003. Given that explorative factor analysis can yield reliable results even for small sample sizes, a principal component analysis (PCA) was used to identify underlying latent constructs and to reveal key challenges and motives. Following this analysis, the retailers were subsequently grouped according to their past and future product-range decisions about locally produced grass-fed beef. Although an analysis of variance (ANOVA) was applied to detect differences between the groups, this study mainly focused on mean and standard deviations to derive tendencies, which was appropriate in view of the small sample size.

\section{RESULTS}

\section{Qualitative Results (Study 1)}

The Dynamics of Stocking Locally Produced Grass-Fed Beef

Seven out of the ten retailers interviewed already stocked locally produced grass-fed beef. Of these seven, one had been among the initiators of the marketing programme for this product, while two other retailers said they wanted to concentrate exclusively on marketing grass-fed beef and only stocked conventionally produced beef as an exception. The remaining three retailers interviewed in the first study did not stock the locally produced grass-fed beef at the time of the interview, though two said they might stock it at some point in the future. One had removed locally produced grass-fed beef from his product range and was not contemplating reintroducing it at any time. The two consultants interviewed for this study stated that about half of the grocery stores under their supervision already stocked locally produced grass-fed beef.

\section{Allocation and Coordination}

Regarding challenges related to the supply chain for local grassfed beef, the interviewees complained about excessively long order periods that required considerable planning and led to increased uncertainty. The interviewees also complained of not being able to re-order single cuts of the product, resulting either in a surplus of locally produced grass-fed beef or limited product availability for customers according to the different purchasing behaviors of these retailers. The interviewees further cited challenges caused by differences in product quality, primarily arising from a lack of product standardization:

The producers should sit down together and find some sort of standard, both in terms of breeds and feed, so that we get more standardized. The product differs too much from producer to producer and from animal to animal. $(L, 35)$

\section{Communication}

Another hurdle reported by the interviewees in terms of marketing the product was the additional communication effort needed to inform customers about the product's elaborate production process. The interviewees stated that direct contact with their customers was very important in this regard, which involved making the staff aware of the added value of locally produced grass-fed beef:

It is always important that the personnel know about the product and can answer questions. Where does the meat come from? How are the animals reared? What type of farming is practiced? $(C, 48)$

The retailer interviewees said that providing their staff with additional training had improved their marketing. They evinced a keen awareness of the crucial importance of staff-customer interactions and had attempted to increase the knowledge of their staff and build their enthusiasm, for example by organizing trips to local farms. They acknowledged the additional efforts entailed in this training but perceived that a lack of sufficiently qualified staff would be a significant hindrance to marketing locally produced grass-fed beef.

Another marketing-related hurdle identified by the interviewees was that of promoting the less popular parts of the meat. Consumers typically prefer prime cuts (e.g., filets), 
and since it was not possible for the retailers to reorder single cuts, they were confronted with the challenge of marketing less popular parts (e.g., as stewing meat) in order to avoid a product surplus or shortage. Some of the interviewees highlighted possible solutions to this problem, especially those who had already had experience in marketing locally produced grass-fed beef. For example, one retailer thought that the problems regarding the re-ordering of smaller cuts could be solved if more retailers added locally produced grass-fed beef to their product range. Others stated that they had found their own solutions to the problem by processing secondary cuts into convenience products (e.g., cooked goulash to be warmed up at home).

\section{Individual Motivations}

Both extrinsic and intrinsic motivations can be identified as drivers for retailers to invest in the marketing of locally produced grass-fed beef. One extrinsic motive cited by the interviewees was that of growing public interest in animal welfare issues. Only a few of the interviewees mentioned financial incentives as the main driver for their investment in marketing the product (Schulze et al., 2019).

Intrinsic motives were cited more often than extrinsic motives. Interviewees highlighted the elaborate production process involved in grass-fed beef, which they related to a high level of animal welfare and environmental protection. For example, among the advantages of grass-fed beef cited by the interviewees were pasture access, grass-fed diets, and the freedom allowed for cattle to exhibit natural behavior, together with the positive implications of these factors for sensory product characteristics such as taste and marbling. They also expressed appreciation of the additional work undertaken by farmers and wanted them to be compensated appropriately for their efforts. The local production process was perceived as beneficial both for supporting local farmers and for bringing together farmers and consumers (Schulze et al., 2019).

\section{Quantitative Results (Study 2)}

Retailer representatives from the regions of BadenWuerttemberg (52.7\%), Rhineland-Palatinate (20.0\%), Saarland (1.8\%), Hesse $(21.8 \%)$, and Bavaria (3.6\%) took part in the survey, thereby representing the regional wholesaler's entire catchment area. More than half of the retailer representatives owned a single grocery store (56.6\%), while the remainder owned more than one store (43.4\%). Most had fewer than 100 employees (74.0\%), while a minority had more than 100 employees (26.0\%). Most of the grocery stores owned by retailers covered an area between 1,001 and 2,500 $\mathrm{m}^{2}$ (75.5\%), while the remaining stores were either smaller $(14.3 \%)$ or larger $(10.2 \%)$. Nearly half of the retailers were over 40 years old (48.9\%), and the majority of the retailer representatives were male (69.1\%) (see Table 2).

A Principal Component Analysis was used to detect the underlying challenges and motives in marketing locally produced grass-fed beef (Table 3 ).

Confirming the findings from the qualitative interviews, the first PCA on challenges faced by retailers identified two factors: "coordination-related challenges" and "communication-related challenges". One item "length of ordering process" was excluded
TABLE 2 | Characteristics of participating retailers in quantitative survey.

\begin{tabular}{|c|c|c|}
\hline Characteristic & $\mathbf{N}$ & $\%$ \\
\hline \multicolumn{3}{|l|}{ Federal state $(n=55)$} \\
\hline Baden-Wuerttemberg & 29 & 52.7 \\
\hline Rhineland-Palatinate & 11 & 20.0 \\
\hline Saarland & 1 & 1.8 \\
\hline Hesse & 12 & 21.8 \\
\hline Bavaria & 2 & 3.6 \\
\hline \multicolumn{3}{|l|}{ Number of markets $(n=53)$} \\
\hline One market & 30 & 56.6 \\
\hline More than one market & 23 & 43.4 \\
\hline \multicolumn{3}{|l|}{ Number of employees $(n=54)$} \\
\hline Fewer than 100 employees & 40 & 74.0 \\
\hline Between 101 and 300 employees & 9 & 16.7 \\
\hline More than 300 employees & 5 & 9.3 \\
\hline \multicolumn{3}{|l|}{ Sales area $(n=51)$} \\
\hline$<1,000 \mathrm{~m}^{2}$ & 7 & 14.3 \\
\hline $1,001-2,500 \mathrm{~m}^{2}$ & 37 & 75.5 \\
\hline Over $2,501 \mathrm{~m}^{2}$ & 5 & 10.2 \\
\hline \multicolumn{3}{|l|}{ Age $(n=45)$} \\
\hline 18-25 years & 3 & 6.7 \\
\hline 26-40 years & 20 & 44.4 \\
\hline $41-65$ years & 22 & 48.9 \\
\hline \multicolumn{3}{|l|}{ Gender $(n=55)$} \\
\hline Female & 17 & 30.9 \\
\hline Male & 38 & 69.1 \\
\hline
\end{tabular}

because of low factor loadings. The factor "coordination-related challenges" refers to variations in quality, seasonal availability, inadequate market supply, and sub-standard quality. Variations in quality were perceived as problematic by $43.4 \%$ of the retailer representatives we surveyed, seasonal availability by $41.5 \%$, inadequate market supply by $28.3 \%$, and sub-standard quality by $30.5 \%$. The factor "communication-related challenges" refers to the marketing of secondary cuts, organic certification, and the training of employees. Marketing secondary cuts (i.e., those that are less attractive to consumers but that also need to be marketed) was perceived as problematic by $53.9 \%$ of the retailer representatives, organic certification by $45.1 \%$, and providing training for employees by $46.3 \%$. Overall, supply-chain challenges were perceived as less problematic $(\mu=2.85)$ than marketing challenges $(\mu=3.35)$.

The two underlying concepts of "self-transcendence" and "self-enhancement," as developed by Schwartz (1992), were assessed in the second PCA. While both values showed a medium to high manifestation level, the retailer representatives identified more strongly with the value of "self-transcendence" $(\mu=4.18)$ than with "self-enhancement" $(\mu=3.45)$.

In the third PCA, the items describing the retailer representatives' perceptions of livestock production can be summarized by the factor "animal welfare awareness" (The item "Generally, people show too little respect for animals" was excluded because of insufficient factor loading). Overall, 
TABLE 3 | Results of the Principal Component Analysis.

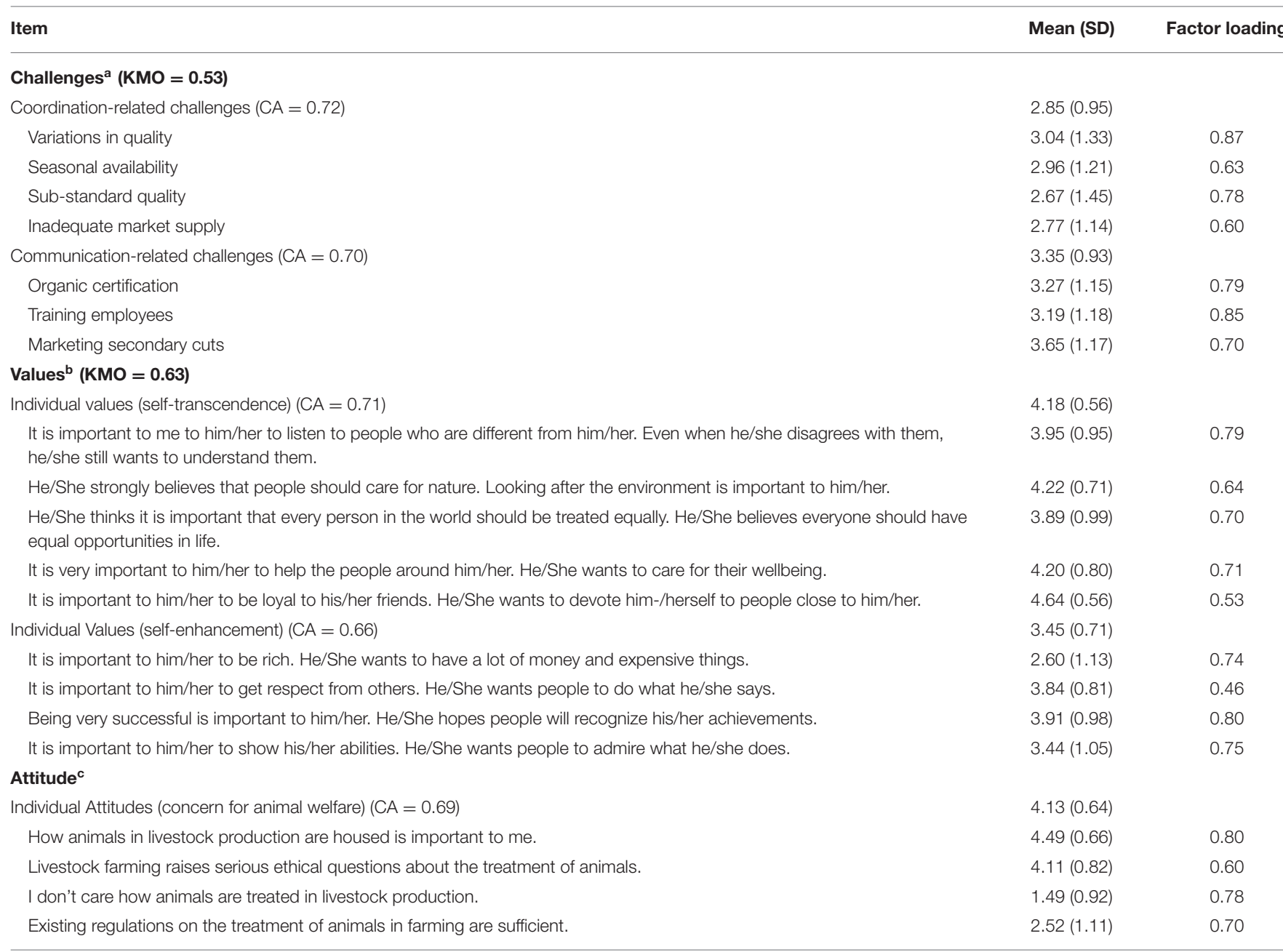

$n=55$, KMO, Kaiser-Meyer-Olkin; CA, Cronbach's Alpha.

${ }^{a}$ On a scale of $1=$ absolutely unproblematic to $5=$ extremely problematic.

b"How much is this person like you?" On a scale of $1=$ not like me at all to $5=$ very much like me.

${ }^{\circ}$ On a scale of $1=$ not true at all to $5=$ absolutely true. Items listed in italics were reverse-coded for reliability analysis.

the sample demonstrated high concern for the welfare of farm animals $(\mu=4.13)$. Financial incentives were perceived as somewhat important in marketing grass-fed beef $(\mu=3.33)$, with $40.0 \%$ of the retailer representatives agreeing with the item "When selling grass-fed beef, financial success is most important," while $20.0 \%$ disagreed and the remaining $20.0 \%$ were unsure.

The retailers were further grouped according to their past and future decisions regarding the stocking of locally produced grassfed beef (see Figure 1), and subsequently labeled according to their perceptions of coordination challenges and communication challenges, their intrinsic motives (self-enhancement, selftranscendence, concern for animal welfare), and their extrinsic motives (financial incentive).

Thus, under the label "niche opponents," we grouped the 22 retailers who did not stock the product and did not plan to do so in the near future. A second group of 18 retailers who did not stock the product but did plan on doing so were termed "niche prospects". Finally, the 15 retailers who already sold the grass-fed beef and wanted to continue selling it in the near future were labeled "niche pioneers". Scores of most important barriers and motivators to retailer groups are shown in Figure 2.

Niche opponents perceived coordination challenges as somewhat problematic $(\mu=2.74, \mathrm{SD}=0.76)$, though to a lesser extent than the two other groups, and perceived marketing-related challenges as the most problematic ( $\mu=3.65$, $\mathrm{SD}=0.75)$. Regarding intrinsic motives, niche opponents somewhat identified with self-enhancement $(\mu=3.36, \mathrm{SD}=$ 0.82 ) but had the lowest level of agreement with this value compared to other groups. Identification with self-transcendence $(\mu=4.02, \mathrm{SD}=0.62)$ was higher among niche opponents 


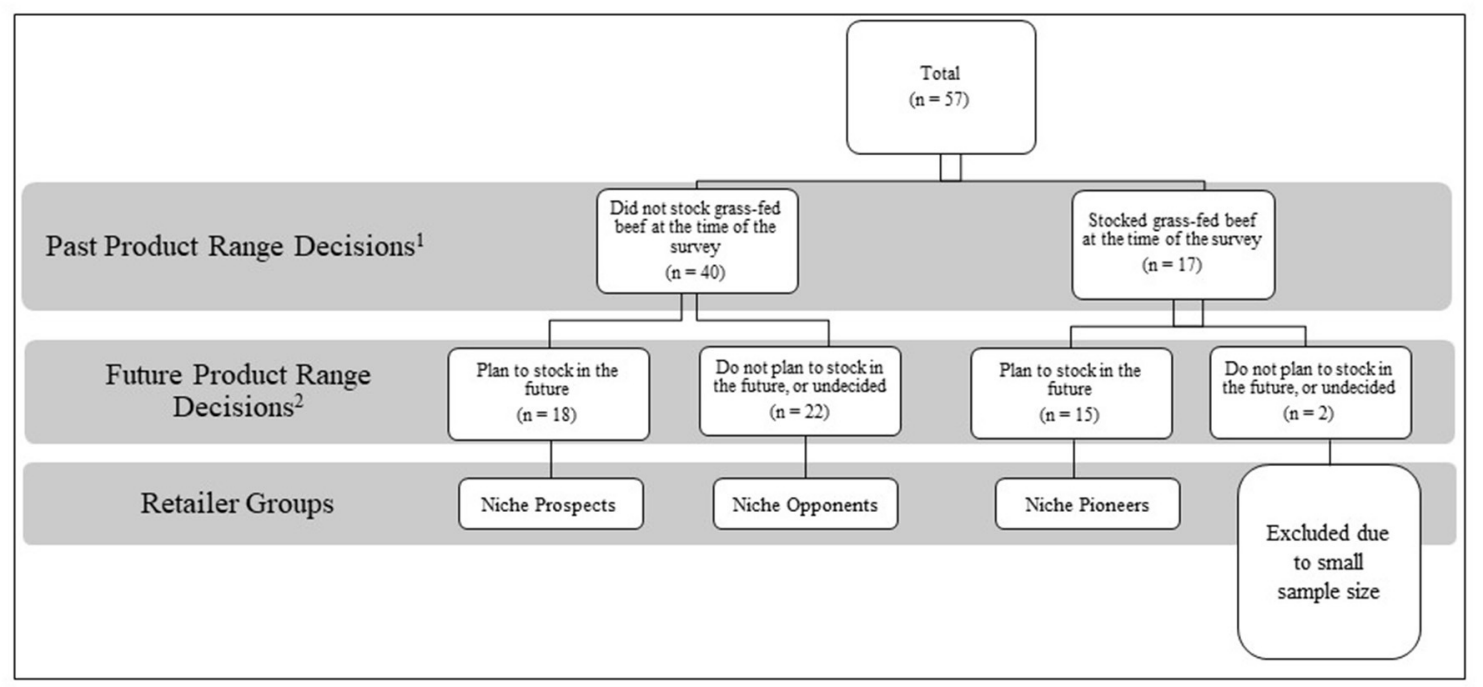

FIGURE 1 | Past and future product-range decisions regarding grass-fed beef. "Based on the question "Does your product range currently include grass-fed beef?" ( 1 = "no, I cannot imagine including it in the future"; 2 = "no, but I am considering introducing it"; 3 = "no, but I have tried it in the past"; 4 = "yes, with moderate success"; 5 = "yes, with considerable success"). ${ }^{2}$ Based on the question "How probable is it that you will stock (or continue to stock) grass-fed beef in 2020 ?" ( 1 = "very unlikely"; 2 = "improbable"; 3 = "undecided"; 4 = "probable"; 5 = "very probable").

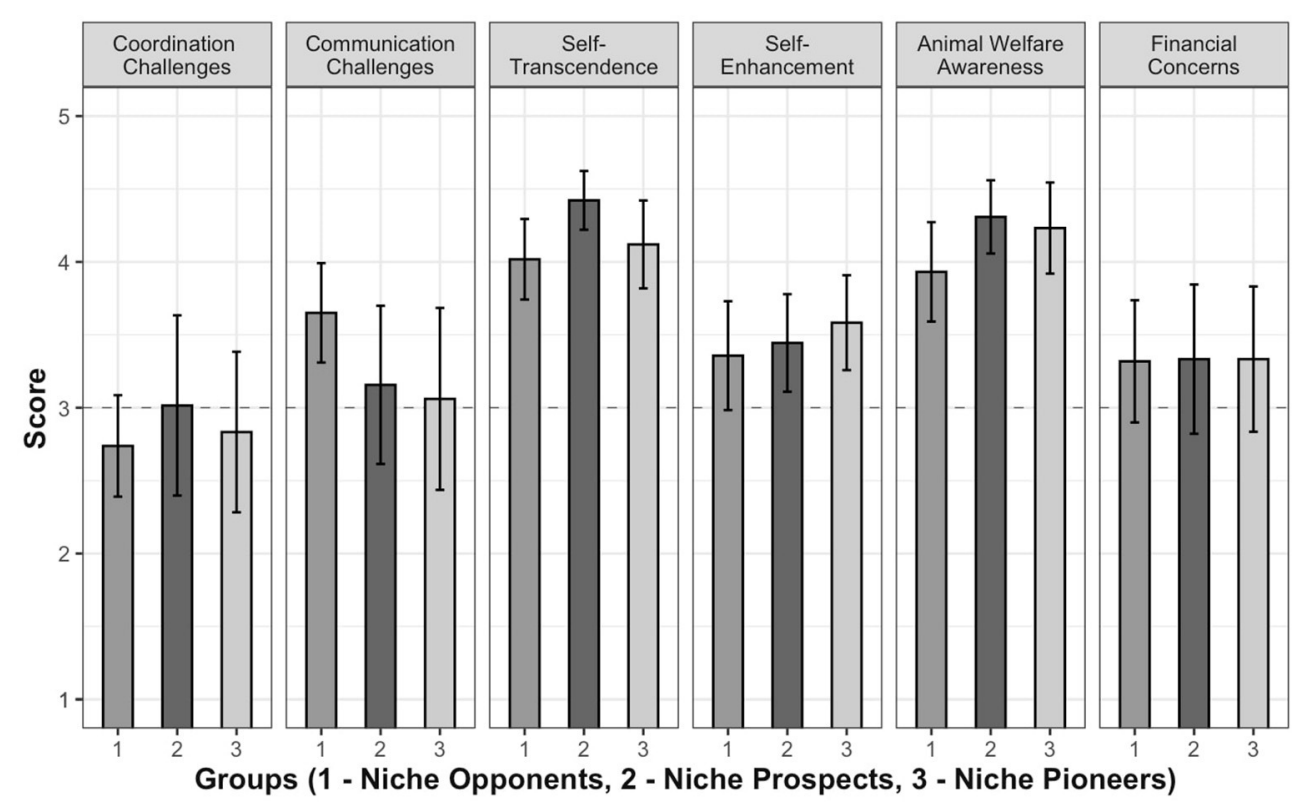

FIGURE 2 | Scores of most important barriers and motivators to retailer groups. Challenges (Coordination- and Marketing-related) on a scale from 1 = "absolutely unproblematic" to $5=$ "extremely problematic". Values (Self-Transcendence and Self-Enhancement) on a scale from $1=$ "not like me at all" to $5=$ "very much like me". Concern for Animal Welfare and Financial Concerns on a scale from $1=$ "not true at all" to $5=$ "totally true". Differences according to ANOVA:

Communication-related challenges: $\left[F_{(2,46)}=2.11, p=0.133\right]$; Coordination-related challenges: $\left[F_{(2,49)}=0.38, p=.687\right]$; Self-transcendence: $\left[F_{(2,52)}=2.91, p=\right.$ 0.064], Self-enhancement: $\left[F_{(2,51)}=0.44, p=0.646\right]$, Concern for animal welfare: $\left[F_{(2,50)}=1.94, p=0.154\right]$, Financial Concerns: $\left[F_{(2,52)}=<0.1, p=0.998\right]$.

than for self-enhancement, though again this group identified with self-transcendence to a lesser extent than either of the other groups. This was also the case regarding levels of concern for animal welfare. While niche opponents had a strong interest in and concern for animal welfare $(\mu=3.93$, SD
$=0.77$ ), their concern was lower than that of either of the other groups. Niche opponents considered financial success to be somewhat important $(\mu=3.32, \mathrm{SD}=0.95)$, roughly at the same level as the other two groups with regard to this motive. 
Niche prospects had the highest mean score regarding perceived challenges related to coordination $(\mu=3.02, \mathrm{SD}=$ 1.16). They also perceived communication challenges as being more problematic than niche pioneers, though to a lesser extent than niche opponents. Regarding intrinsic drivers, the niche prospects group identified more strongly with self-enhancement ( $\mu=3.44, \mathrm{SD}=0.67$ ) than niche opponents, and the same applied for self-transcendence $(\mu=4.42, \mathrm{SD}=0.41)$. The niche prospect group's identification with self-transcendence was the highest of all three groups, and this was also the case for concern for animal welfare $(\mu=4.31, \mathrm{SD}=0.49)$. Financial success was perceived as somewhat important for niche prospects $(\mu=3.33$, $\mathrm{SD}=1.03$ ).

Niche pioneers perceived coordination challenges as somewhat problematic $(\mu=2.83, \mathrm{SD}=0.99$ ), i.e., to a lesser extent than niche prospects but more so than niche opponents. Niche pioneers also viewed communication challenges as somewhat problematic $(\mu=3.06, \mathrm{SD}=0.93)$, though less so than the other two groups. Niche pioneers had the highest identification with self-enhancement $(\mu=3.58, \mathrm{SD}=0.59)$, while their identification with self-transcendence $(\mu=4.12, \mathrm{SD}=0.54)$ and their concern for animal welfare $(\mu=4.23, \mathrm{SD}=0.54)$ was lower compared to niche prospects but higher than that of niche opponents. Financial success was perceived as somewhat important for niche pioneers $(\mu=3.33, \mathrm{SD}=0.90)$.

\section{DISCUSSION}

The results from both the quantitative and the qualitative studies revealed here confirm that independent business structures in food retail cooperatives contribute to the transition toward sustainable marketing initiatives in food retailing. The approach in this study is unique in that the sample on which it is based was gathered from a large cooperative in order to investigate the capacity of cooperative structures to support retailers in pursuing alternative strategies for the effective distribution and retailing of sustainable produce. Based on their alternative marketing strategies and their relevance in the sustainable transition process, these cooperatives can be called co-ops 2.0. By specifically looking at large-scale cooperative structures, with a special focus on cooperation and coordination, this study thus provides significant insights both for the development of initiatives that promote local and regional food heritage in the retail sector and for the development of effective marketing of sustainably produced food.

Overall, we found a high proportion of niche pioneers and niche prospects in this sample, with only $39 \%$ of the retailers classifiable as niche opponents. However, the food retailers who support the distribution of sustainable produce still face numerous challenges in developing a new business model for retailing sustainable food. The results of both studies revealed challenges in coordination and communication, both of which are important aspects in the distribution of sustainable produce. However, those retailers who are interested in investing in alternative marketing approaches (niche prospects) evinced lower levels of concern about communication and coordination challenges than the group of niche opponents. Interestingly, the niche pioneers who were already involved as key actors in the development of alternative distribution channels evinced less concern about these challenges than the group of niche prospects. It seems that being part of a newly built marketing approach reduces the level of concern about challenges. This finding is consistent with previous results from Silvestre et al. (2020) and Gong et al. (2018) showing that a sustainable transition is not possible without learning processes. Learning processes are especially important in retailing sustainably produced foods, since regardless of how great a retailer's motivation may be to participate in a new marketing approach, the actual implementation of sustainable marketing initiatives inevitably involves challenges related to coordination that require support to be overcome.

Moreover, niche pioneers and niche prospects showed higher concern for animal welfare as well as identified themselves more with the self-transcendence value. Thus, in line with Papagiannakis and Lioukas (2012), results of this study revealed that individual values and attitudes influence retailers' product range decisions. Moreover, in accordance with results from Andersson and Bateman (2000) descriptive results of this study indicated that if changes that occur within a sustainable transition are in line with food retailers' individual values and attitudes (e.g. concern for animal welfare) they are more open to make sustainable product range decisions.

According to Geels (2004), providing structure for actors pursuing transition offers the possibility of greater coordination and stability. Applying this finding to niche pioneers in the food retail industry, it can be argued that the business structure of food retailers' cooperatives provides such structure in the form of marketing support and network contacts, helping these niche pioneers to overcome challenges and thus making changes less problematic. With regard to the retailers in the niche prospects group, the existing interest of these retailers in investing in alternative marketing approaches may explain why they evinced fewer concerns about challenges than the group of niche opponents. Meanwhile, the fact that the group of niche prospects has not yet made use of the support of the food cooperative to sell and market grass-fed beef may explain why its concerns about the challenges involved were greater than the concerns of niche pioneers. This result is in line with previous work by Silva et al. (2021) showing that collaboration with suppliers is key to pursue sustainability in the supply chain.

This study suggests that membership of the food cooperative allows retailers to take advantage of its business structures, providing them with sufficient flexibility to make their own decisions about participating in sustainable initiatives while still retaining the option of falling back on the support of the cooperative (for example, by seeking advice from marketing consultants). Thus, this business structure allows to share information, reduce costs, and to provide a strategic alliancecharacteristics that are advantages of a collaboration (Chen et al., 2017). This business structure thus allows for the development of alternative paths in niches that deviate from prevailing marketing approaches in food retail, including trends toward ever-greater centralization and mass production (Geels, 2004). This business 
structure thus allows for the development of alternative paths in niches that deviate from prevailing marketing approaches in food retail, including trends toward ever-greater centralization and mass production (Geels, 2004). The business structure of food cooperatives has the scale and capacity to boost the marketing of sustainably produced food and thus adopt sustainable marketing initiatives developed in niches. This structure may be suitable for developing alternative paths within the back-up structure of a cooperative, thereby providing space for learning processes to occur (Geels, 2004).

A successful transition toward more sustainable food retail depends on the timing and nature of interactions (Geels and Schot, 2007). In this respect, the growing interest of consumers in sustainable food consumption and increasing concerns about animal welfare (Aleksandrowicz et al., 2016; Busch et al., 2018; Godfray et al., 2018), combined with negative externalities of mass food production such as the environmental impacts of this prevailing form of production (Godfray and Garnett, 2014), may constitute a "window of opportunity" for the breakthrough of radical changes in food retail (Geels, 2004). Confronted with increasing public interest in more sustainable food production and consumption, conventional food retailers may eventually respond by employing their considerable adaptive capacity to reorient their business practices, fostering changes across the whole industry (Geels and Schot, 2007). Especially, alternative distribution channels for sustainably produced food offer great potential to communicate the society-serving impact of food retailers' efforts, which has a positive impact on customer satisfaction and loyalty intentions (Bolton and Mattila, 2015) and thus, in turn, will facilitate the sustainability transition in food retailing. The sustainability transition should further be supported by information-based strategies that provide verbal informational messages to make consumers aware of the benefits of retailers' efforts to facilitate the transition (Gleim et al., 2013).

Although alternative marketing challenges have not yet been sufficiently developed to lead to fundamental changes in conventional food retail, we argue on the basis of the findings that undertaking such initiatives in parallel with increasing public pressure could serve to modify the direction of future developments in food retail. The establishment of successful and sustainable distribution channels in niches may influence the views of other actors in the food retail sector by providing an alternative perspective that could lead to reorientations in this sector. Food retailers who adopt alternative marketing initiatives that deviate from conventional food retailing can thus act as front-runners in the transition to more sustainable food retailing (Geels and Schot, 2007). However, it should be noted that a sustainable transition is complex and thus, cannot be pursued by food retailers alone. Other stakeholders as well as politicians should be considered as well.

This study further reveals that food cooperatives provide support for coordination and cooperation in such a way that allows retailers to develop alternative marketing channels while still remaining part of the conventional food retail sector, in contrast, in this respect, to other models of sustainable transition that follow the "transformation pathway" (Smith, 2006; Geels and Schot, 2007). In this sense, food cooperatives are part of the prevailing "regime" but at the same time have the structural capacity to provide protected spaces for retailers to pursue sustainable niche developments. This structure enables food cooperatives to be fast adopters of innovations. Providing space for alternative marketing channels further provides food cooperatives with extensive opportunities to observe developments in niche innovations, thereby reducing the level of risk and uncertainty entailed in adopting such innovations. Since cooperatives are already part of the conventional system, they can moreover draw upon their established structure, knowledge, and social networks to help retailers adopt alternative marketing channels that may in turn foster a successful transition to more sustainable food retailing.

\section{CONCLUSION}

The business organization of food cooperatives provides a structure that can help retailers overcome the initial challenges involved in the retail of sustainably produced local food, harnessing their motives to further enhance and channel the successful marketing of these products. The cooperative marketing environment could be used to establish new approaches to address the challenges of communication and of coordination. Indeed, it can be further suggested that retailers could use perceived coordination challenges as opportunities. For example, the variable product characteristics of grass-fed beef that stem from the less standardized production process, such as marbling, could be emphasized to highlight the uniqueness of the product, while variations in seasonal availability could be used to enhance demand in specific seasons. This marketing approach is already known from the retailing of strawberries and asparagus and could also be used to promote the sale of this and other non-standardized sustainable local products.

Cooperatives should provide retailers with the access to as much information as possible about effective ways to overcome these initial challenges of selling sustainably produced local food. Communication and coordination remain the main challenges that may be taken up and efficiently united by structures like the studied cooperative ones. For example, solutions developed by niche pioneers should be used as models to encourage the groups that have been labeled here as "niche prospects" and "niche opponents" to stock these products. The consultants of cooperatives could help spread this information, since they are in contact with a wide range of different retailers. Retailers and farmers should jointly discuss further developments and solutions to these initial challenges, including how to cope with variations in quality and seasonal product availability. For example, some of the retailers who participated in the study had already found solutions for processing and marketing secondary cuts of meat by processing them into convenience products, and these solutions could serve as models for other retailers. Given that not all retailers are able to implement such practices, a further element in this solution might be to organize the processing of less popular parts cooperatively. Finally, the results of this study emphasize the strong influence of intrinsic motivation for key actors in food retailing, suggesting that all cooperatives seeking to foster more sustainable food retailing should consider values and attitudes in their selection process. 
However, this research has limitations. First, results are based on a small sample size and thus, only tendencies can be derived. Second, this research solely investigated the leading German food retail cooperative. Due to its size and organizational structure the cooperative offers great potential to investigate the role of food retail cooperatives. However, further research should try to confirm the results from this study for other cooperatively organized food retail companies in Europe.

\section{DATA AVAILABILITY STATEMENT}

The raw data supporting the conclusions of this article will be made available by the authors, without undue reservation.

\section{ETHICS STATEMENT}

Ethical review and approval was not required for the study on human participants in accordance with the local legislation and institutional requirements. Written informed consent for participation was not required for this study in accordance with the national legislation and the institutional requirements.

\section{REFERENCES}

Agrarmarkt Informations Gesellschaft (AMI) (2021) AMI Markt Bilanz Vieh und Fleisch 2021. Rheinbreitbach: Plump Druck and Medien GmbH.

Aleksandrowicz, L., Green, R., Joy, E. J. M., Smith, P., and Haines, A. (2016). The impacts of dietary change on greenhouse gas emissions, land use, water use, and health: a systematic review. PLOS ONE 11:e0165797. doi: 10.1371/journal.pone.0165797

Andersson, L. M., and Bateman, T. S. (2000). Individual environmental initiative: championing natural environmental issues in US business organizations. Acad. Manag. J. 43, 548-570. doi: 10.5465/1556355

Bolton, L. E., and Mattila, A. S. (2015). How does corporate social responsibility affect consumer response to service failure in buyer-seller relationships? J. Retail. 91, 140-153. doi: 10.1016/j.jretai.2014.10.001

Bui, S., Costa, I., De Schutter, O., Dedeurwaerdere, T., Hudon, M., and Feyereisen, M. (2019). Systemic ethics and inclusive governance: two key prerequisites for sustainability transitions of agri-food systems. Agric. Hum. Values 36, 277-288. doi: 10.1007/s10460-019-09917-2

Busch, G., Gauly, M., and Spiller, A. (2018). What needs to be changed for successful future livestock farming in Europe? Animal 12, 1999-2001. doi: $10.1017 /$ S1751731118001258

Chen, L., Zhao, X., Tang, O., Price, L., Zhang, S., and Zhu, W. (2017). Supply chain collaboration for sustainability: a literature review and future research agenda. Int. J. Prod. Econ. 194, 73-87. doi: 10.1016/j.ijpe.2017.04.005

El Bilali, H. (2019). The multi-level perspective in research on sustainability transitions in agriculture and food systems: a systematic review. Agriculture 9, 1-24. doi: 10.3390/agriculture9040074

Esbjerg, L., Burt, S., Pearse, H., and Glanz-Chanos, V. (2016). Retailers and technology-driven innovation in the food sector: Caretakers of consumer interests or barriers to innovation? Br. Food J. 118, 1370-1383. doi: 10.1108/BFJ-10-2015-0367

Eurostat (2021). Purchasing Power Parities. Available online at: http://appsso. eurostat.ec.europa.eu/nui/submitViewTableAction.do Available online at: https://ec.europa.eu/eurostat/statistics-explained/index.php?title= Comparative_price_levels_of_consumer_goods_and_services\#Price_levels_ for_food.2C_beverages.2C_tobacco.2C_clothing_and_footwear (accessed August 13, 2021).

Geels, F. W. (2004). From sectoral systems of innovation to socio-technical systems: Insights about dynamics and change from sociology and institutional theory. Res. Policy 33, 897-920. doi: 10.1016/j.respol.2004.01.015

\section{AUTHOR CONTRIBUTIONS}

MS, AR, and AS contributed to conception and design of the study. MS conducted data analysis, supervised by AR. MS and AR wrote the manuscript. AS revised the manuscript. All authors contributed to the interpretation of the results, manuscript revision, read, and approved the submitted version.

\section{FUNDING}

This work was supported by the Federal Office for Agriculture and Food, Germany (BLE 2818301416) and the Ministry of Science and Arts (MWK) in Lower Saxony, Germany. The authors were responsible for the content of this publication.

\section{ACKNOWLEDGMENTS}

The project on which this contribution is based was conducted with research-oriented learning in collaboration with the student Pia Skroch.

Geels, F. W., and Schot, J. (2007). Typology of sociotechnical transition pathways Res. Policy 36, 399-417. doi: 10.1016/j.respol.2007.01.003

Gleim, M. R., Smith, J. S., Andrews, D., and Joseph Cronin, J. (2013). Against the Green: a multimethod examination of the barriers to green consumption. J. Retail. 89, 44-61. doi: 10.1016/j.jretai.2012.10.001

Godfray, H. C. J., Aveyard, P., Garnett, T., Hall, J. W., Key, T. J., Lorimer, J., et al. (2018). Meat consumption, health, and the environment. Science 361:eaam5324. doi: 10.1126/science.aam5324

Godfray, H. C. J., and Garnett, T. (2014). Food security and sustainable intensification. Philos. Trans. R. Soc. B 369:20120273. doi: 10.1098/rstb.2012.0273

Gong, Y., Jia, F., Brown, S., and Koh, L. (2018). Supply chain learning of sustainability in multi-tier supply chains: a resource orchestration perspective. Int. J. Oper. Prod. Manag. 38, 1061-1090. doi: 10.1108/IJOPM-05-2017-0306

Holtz, G., Brugnach, M., and Pahl-Wostl, C. (2008). Specifying 'regime': a framework for defining and describing regimes in transition research. Technol. Forecast. Soc. Change 75, 623-643. doi: 10.1016/j.techfore.2007.02.010

Immink, V. M., Reinders, M. J., van Tulder, R. J. M., and van Trijp, J. C. M. (2013). The livestock sector and its stakeholders in the search to meet the animal welfare requirements of society [Special issue]. J. Chain Netw. Sci. 13, 151-160. doi: 10.3920/JCNS2013.1005

Kendall, H. A., Lobao, L. M., and Sharp, J. S. (2006). Public concern with animal well-being: place, social structural location, and individual experience. Rural Sociol. 71, 399-428. doi: 10.1526/003601106778070617

Kneafsey, M., Venn, L., Schmutz, U., Balázs, B., Trenchard, L., Eyden-Wood, T., et al. (2013). Short Food Supply Chains and Local Food Systems in the EU. A State of Play of Their Socio-Economic Characteristics. Brussels: European Commission. Available online at: https://pureportal.coventry.ac.uk/en/ publications/short-food-supply-chains-and-local-food-systems-in-the-eu-astate-2 (accessed August 13, 2021).

Lachman, D. A. (2013). A survey and review of approaches to study transitions. Energy Policy 58, 269-276. doi: 10.1016/j.enpol.2013.03.013

Mastronardi, L., Marino, D., Cavallo, A., and Agostino, G. (2015). Exploring the role of farmers in short food supply chains: the case of Italy. Int. Food Agribus. Manag. Rev. 18, 109-130. doi: 10.22004/ag.econ.204139

Mayring, P. (2010). Qualitative Inhaltsanalyse: Grundlagen und Techniken. Weinheim: Beltz.

Nielsen Trade Dimensions (2019). Top-Firmen Edition 2019. Reported in fleischwirtschaft.de (24 November 2019: 'Die Top 5 bleiben an der Spitze'). Available online at: https://www.fleischwirtschaft.de/wirtschaft/charts/ 
Lebensmittelhandel-Die-Top-5-bleiben-an-der-Spitze- 40682

(accessed August 13, 2021).

Palinkas, L. A., Aarons, G. A., Horwitz, S. M., Chamberlain, P., Hurlburt, M., and Landsverk, J. (2011). Mixed method designs in implementation research. Adm. Policy Ment. Health Ment. Health Serv. Res. 38, 44-53. doi: 10.1007/s10488-010-0314-Z

Papagiannakis, G., and Lioukas, S. (2012). Values, attitudes and perceptions of managers as predictors of corporate environmental responsiveness. J. Environ. Manag. 100, 41-51. doi: 10.1016/j.jenvman.2012.01.023

Pearson, D., Henryks, J., Trott, A., Jones, P., Parker, G., Dumaresq, D., et al. (2011). Local food: understanding consumer motivations in innovative retail formats. Br. Food J. 113, 886-899. doi: 10.1108/00070701111148414

Peattie, K., and Peattie, S. (2009). Social marketing: a pathway to consumption reduction? J. Bus. Res. 62, 260-268. doi: 10.1016/j.jbusres.2008.01.033

Porter, M. E. (1980). Competitive Strategy: Techniques for Analyzing Industries and Competitors. New York, NY: Free Press.

Sands, S., Oppewal, H., and Beverland, M. (2009). The effects of in-store themed events on consumer choice decisions. J. Retail. Consum. Serv. 16, 386-395. doi: 10.1016/j.jretconser.2009.05.001

Schulze, M., and Risius, A. (2019). "Warenverfügbarkeit als Hemmnis in der Vermarktung von Biorindfleisch-die Perspektive des Lebensmitteleinzelhandels," in Innovatives Denken für eine nachhaltige Landund Ernährungswirtschaft. Beiträge zur 15. Wissenschaftstagung Ökologischer Landbau, Kassel, 5. bis 8. März 2019, eds D. Mühlrath, J. Albrecht, M. R. Finckh, U. Hamm, J. Heß, U. Knierim, and D. Möller 5 (Berlin: Verlag Dr. Köster).

Schulze, M., Spiller, A., and Risius, A. (2019). Food retailers as mediating gatekeepers between farmers and consumers in the supply chain of animal welfare meat: studying retailers' motives in marketing pasture-based beef. Food Ethics 3, 41-52. doi: 10.1007/s41055-019-00040-w

Schwartz, S. H. (1992). Universals in the content and structure of values: theoretical advances and empirical tests in 20 countries. Adv. Exp. Soc. Psychol. 25, 1-65. doi: 10.1016/S0065-2601(08)60281-6

Sexton, R., and Xia, T. (2018). Increasing concentration in the agricultural supply chain: Implications for market power and sector performance. Ann. Rev. Resour. Econ. 10, 229-251. doi: 10.1146/annurev-resource-100517-023312
Silva, M. E., Dias, G. P., and Gold, S. (2021). Exploring the roles of lead organisations in spreading sustainability standards throughout food supply chains in an emerging economy. Int. J. Logist. Manag. 32, 1030-1049. doi: 10.1108/IJLM-05-2020-0201

Silvestre, B. S., Silva, M. E., Cormack, A., and Thome, A. M. T. (2020). Supply chain sustainability trajectories: learning through sustainability initiatives. Int. J. Oper. Prod. Manag. 40, 1301-1337. doi: 10.1108/IJOPM-01-2020-0043

Smith, A. (2006). Green niches in sustainable development: the case of organic food in the United Kingdom. Environ. Plann. C Polit. Space 24, 439-458. doi: $10.1068 / \mathrm{c} 0514 \mathrm{j}$

Vadakkepatt, G. G., Winterich, K. P., Mittal, V., Zinn, W., Beitelspacher, L., Aloysius, J., et al. (2020). Sustainable retailing. J. Retail. 97, 62-80. doi: 10.1016/j.jretai.2020.10.008

Vittersø, G., Torjusen, H., Laitala, K., Tocco, B., Biasini, B., Csillag, P., et al. (2019). Short food supply chains and their contributions to sustainability: participants' views and perceptions from 12 European cases. Sustainability 11:4800. doi: 10.3390/su11174800

Conflict of Interest: The authors declare that the research was conducted in the absence of any commercial or financial relationships that could be construed as a potential conflict of interest.

Publisher's Note: All claims expressed in this article are solely those of the authors and do not necessarily represent those of their affiliated organizations, or those of the publisher, the editors and the reviewers. Any product that may be evaluated in this article, or claim that may be made by its manufacturer, is not guaranteed or endorsed by the publisher.

Copyright (c) 2021 Schulze, Spiller and Risius. This is an open-access article distributed under the terms of the Creative Commons Attribution License (CC BY). The use, distribution or reproduction in other forums is permitted, provided the original author(s) and the copyright owner(s) are credited and that the original publication in this journal is cited, in accordance with accepted academic practice. No use, distribution or reproduction is permitted which does not comply with these terms. 